\title{
The influence of processing objectives on the perception of faces: An ERP study of race and gender perception
}

\author{
TIFFANY A. ITO and GEOFFREY R. URLAND \\ University of Colorado, Boulder, Colorado
}

\begin{abstract}
In two experiments, event-related potentials were used to examine the effects of attentional focus on the processing of race and gender cues from faces. When faces were still the focal stimuli, the processing of the faces at a level deeper than the social category by requiring a personality judgment resulted in early attention to race and gender, with race effects as early as $120 \mathrm{msec}$. This time course corresponds closely to those in past studies in which participants explicitly attended to target race and gender (Ito \& Urland, 2003). However, a similar processing goal, coupled with a more complex stimulus array, delayed social category effects until $190 \mathrm{msec}$, in accord with the effects of complexity on visual attention. In addition, the N170 typically linked with structural face encoding was modulated by target race, but not by gender, when faces were perceived in a homogenous context consisting only of faces. This suggests that when basic-level distinctions between faces and nonfaces are irrelevant, the mechanism previously associated only with structural encoding can also be sensitive to features used to differentiate among faces.
\end{abstract}

One of our most important daily activities is to make sense of the people we encounter, to infer their motives and emotions and what this implies for our well-being. In many cases, this information can be gleaned from the faces of those around us, and not surprisingly, face perception has been an active area of investigation among neuroscientists. Some of the frequently studied aspects of facial perception include the differentiation of faces from nonfaces (e.g., Bentin, Allison, Puce, Perez, \& McCarthy, 1996; Eimer, 2000; Kanwisher, McDermott, \& Chun, 1997), the recognition of personal identity (e.g., Bentin \& Deouell, 2000; Eimer, 2000; Hoffman \& Haxby, 2000), and the perception of emotion (e.g., Adolphs, Tranel, \& Damasio, 1994; Balconi \& Pozzoli, 2003; Eimer, Holmes, \& McGlone, 2003; Morris, Frith, \& Perrett, 1996). Theoretically, it has also been recognized that information indicative of social category membership - cues related to such things as race, gender, and age - can be readily determined from faces, but this issue has received less attention among neuroscientists. Consequently, such issues as time course, relation to other aspects of face processing, and attentional influences on this process are not well understood.

Researchers who have investigated how group membership is processed have found that it can be encoded relatively easily and early in processing. Mouchetant-

This research was supported by National Institute of Mental Health Grants 1R03 MH61327 and 1R21 MH66739 to T.A.I. and by a National Science Foundation Graduate Research Fellowship to G.R.U. We are grateful to Keith Brown and Erin Thompson for assistance with data collection. Correspondence concerning this article should be addressed to T. A. Ito, Department of Psychology, University of Colorado, 345 UCB, Boulder, CO 80309-0345 (e-mail: tito@psych.colorado.edu).
Rostaing and Giard (2003) found that when perceivers viewed faces differing in gender or age, as compared with faces from a single category (e.g., all males), eventrelated potential (ERP) responses at frontal-central areas were modulated as early as $145 \mathrm{msec}$. That is, electrophysiological activity varied when a differentiation could be made between social categories (male vs. female), as compared with when the social category was the same for all the targets. This occurred both when perceivers were explicitly attending to gender or age and when social categorization was task irrelevant (see also MouchetantRostaing, Giard, Bentin, Aguera, \& Pernier, 2000).

Ito and Urland (2003) found similarly early social category effects at frontal-central areas. Race affected ERP responses by about $120 \mathrm{msec}$, whereas gender effects occurred slightly later, by about $180 \mathrm{msec}$. Both effects occurred regardless of whether the participants were explicitly attending to race or gender. In addition, whereas Mouchetant-Rostaing and colleagues (MouchetantRostaing \& Giard, 2003; Mouchetant-Rostaing et al., 2000) examined responses as a function of whether gender or age differentiation was possible (i.e., whether there was variability in the faces along those dimensions), Ito and Urland examined responses as a function of the specific group (i.e., how responses to Whites vs. Blacks and males vs. females differed). This provides information not only on the degree to which category distinctions are made, but also on the direction of attentional focus to specific groups throughout processing. These analyses revealed that at the first point of race modulation, which was seen in the N100 (mean peak latency around $120 \mathrm{msec}$ ), responses were larger to Blacks than to Whites. At the first point of gender modulation, which occurred in the P200 
(mean peak latency around $180 \mathrm{msec}$ ), responses were larger to males than to females. P200s were also larger to Blacks than to Whites. Importantly, all the effects occurred regardless of whether the participants were explicitly categorizing the faces in terms of race or gender.

In the N200, the effects were reversed, with larger responses to Whites and females than to Blacks and males, respectively. Again, this occurred regardless of task. Whereas the N100, P200, and N200 were insensitive to the relation between a target stimulus and the preceding faces, the P300 did vary as a function of preceding faces. Consistent with past P300 research (e.g., Donchin, 1981), P300s were larger when a target individual's social category membership differed from the preceding individuals on the task-relevant dimension (as compared with when it matched the preceding context). Thus, working memory processes were sensitive to the social category dimension along which categorization was occurring explicitly. Implicit categorization effects were also obtained; P300 amplitude also increased when a target picture differed from the individuals pictured in preceding pictures along the task-irrelevant dimension.

As can be seen, these past studies demonstrate that social category information can quickly and easily influence face processing. The question we address here is whether early encoding processes oriented toward social category information can be modified. There are a number of tasks that succeed in attenuating stereotyping and prejudice (e.g., Fiske \& Neuberg, 1990). That is, they influence the cognitions and affect thought to be activated by social category information. This suggests the possibility that attention to social category information has been altered by the task. However, prominent theories of social perception argue that the mere presentation of a stimulus person is sufficient to produce identification of the target's social category membership (Brewer, 1988; Fiske \& Neuberg, 1990; Macrae \& Bodenhausen, 2000). This position suggests that the locus of any attentional effects on the processing of social category information will occur later in processing, after initial perceptual-level processing. To address this, two experiments are reported in which we examine how the effects obtained in Ito and Urland (2003), whose participants were explicitly attending to either race or gender information, are affected by manipulations known to attenuate stereotyping and prejudice.

The experiments reported here have a secondary goal of examining the interrelation between structural face encoding and assessment of social category information. According to Bruce and Young (1986), structural face encoding and extraction of social category information (which they refer to as visually derived semantic information) are mediated by separate, sequentially occurring processing stages, with social category processing being dependent on prior structural encoding. In ERP research, structural encoding has been consistently linked to the N170 component (Bentin et al., 1996; Eimer, 2000). The model proposed by Bruce and Young would, therefore, predict that N170s should be insensitive to social category information. By contrast, research on expertise has shown an increase in an N170-like component to nonface stimuli about which perceivers are expert (Tanaka $\&$ Curran, 2001). On the basis of this, the $\mathrm{N} 170$ has been conceived as reflecting a more general expertise mechanism that is sensitive to faces, about which humans are normally considered expert, and to other stimuli about which individuals are idiosyncratically expert. From this perspective, N170s to faces may be expected to vary as a function of experience with different types of faces. Given that perceivers typically have more experience with members of their own groups, N170s may be larger to ingroup than to outgroup faces. Results relevant to this issue have been mixed. Among four studies in which the N170 or its apparent positive dipole, the vertex positive potential (VPP), was examined as a function of target race, N170s/VPPs have been larger to faces than to nonfaces but equally large to ingroup and outgroup faces (Caldara, Rossion, Bovet, \& Hauert, 2004; Caldara et al., 2003; Ito, Thompson, \& Cacioppo, 2004). That larger N170s were obtained to familiar than to unfamiliar faces, however, seems consistent with the domain-general expertise/familiarity explanation (Caharel, Poiroux, \& Bernard, 2002). This issue will, therefore, be examined further in the present study.

\section{EXPERIMENT 1}

In order to examine the effects of attentional manipulations on the perceptions of social category information, focus of attention was varied as the participants viewed faces varying in race. Attention was manipulated through the adoption of different processing goals, rather than some other, frequently used manipulations, such as spatial attention, because the former are known to affect stereotyping and prejudice. Thus, these manipulations produce measurable differences in how faces are perceived (Macrae, Bodenhausen, Milne, Thorn, \& Castelli, 1997; Wheeler \& Fiske, 2005). The participants in Experiment 1 performed either an individuation or a visual feature detection task. In the case of individuation, attention is focused primarily on the target's individual attributes and characteristics, rather than on his or her social category memberships, encouraging a level of processing deeper than the social category. The individual person, rather than the social category, is the basis for encoding and organizing information (Brewer, 1988). In the case of visual feature detection, attention is focused away from both the social category and the individual person attributes through a task that requires attention to a nonsocial visual feature (a white dot). In this way, a level of analysis more shallow than the social category is encouraged, and the encoding and organization of information is more likely to be organized in terms of the dot cue (Macrae et al., 1997).

\section{Method}

\section{Participants and Overview}

Twenty-eight students (14 females) from the University of Colorado participated for partial fulfillment of class requirements. Two males and 1 female identified their race as Asian American. All 


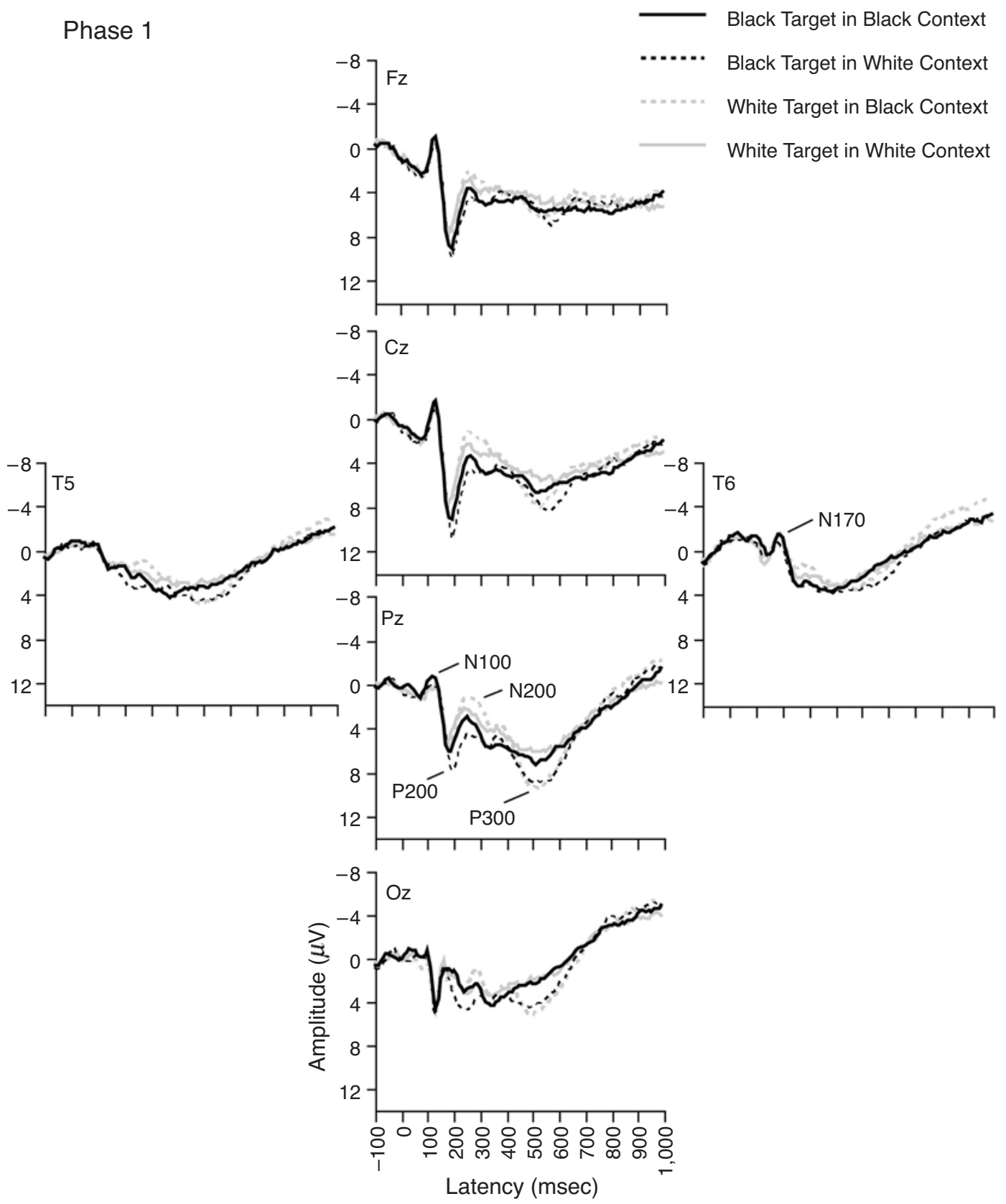

Figure 1. Grand average event-related potential waveforms from Phase 1 of Experiment 1 at selected sites as a function of target and context race. In Phase 1, the participants performed either the vegetable or the dot task. Waveforms are collapsed across vegetable or dot task, because there was only one difference (in the N100) between the two tasks. The N170, visible at temporal sites, is indicated at T6. The N100, P200, N200, and P300, visible at midline sites, are indicated at $\mathrm{Pz}$.

others identified themselves as White. ${ }^{1}$ All viewed pictures of Black and White males in two phases of the experiment. In the first phase, half of the participants were randomly assigned to judge whether each individual liked different types of vegetables (the individuation task). This task has been shown to decrease stereotype activation and the typically greater amygdala activation to racial outgroup than to ingroup faces thought to reflect greater negativity toward the outgroup (Wheeler \& Fiske, 2005). The remaining participants judged whether there was a dot on each picture in Phase 1 (the nonsemantic visual detection task), a task also shown to decrease stereotype activation (Macrae et al., 1997). In the second phase of the experiment, all the participants viewed the stimuli again while making explicit racial categorization judgments, thereby allowing a comparison within the study to processing during explicit social categorization. Because we required a larger number of trials, we limited our investigation to only a single social categorization dimension, choosing race because it had earlier and larger effects than did gender in our past research (Ito \& Urland, 2003). 


\section{Phase 2}
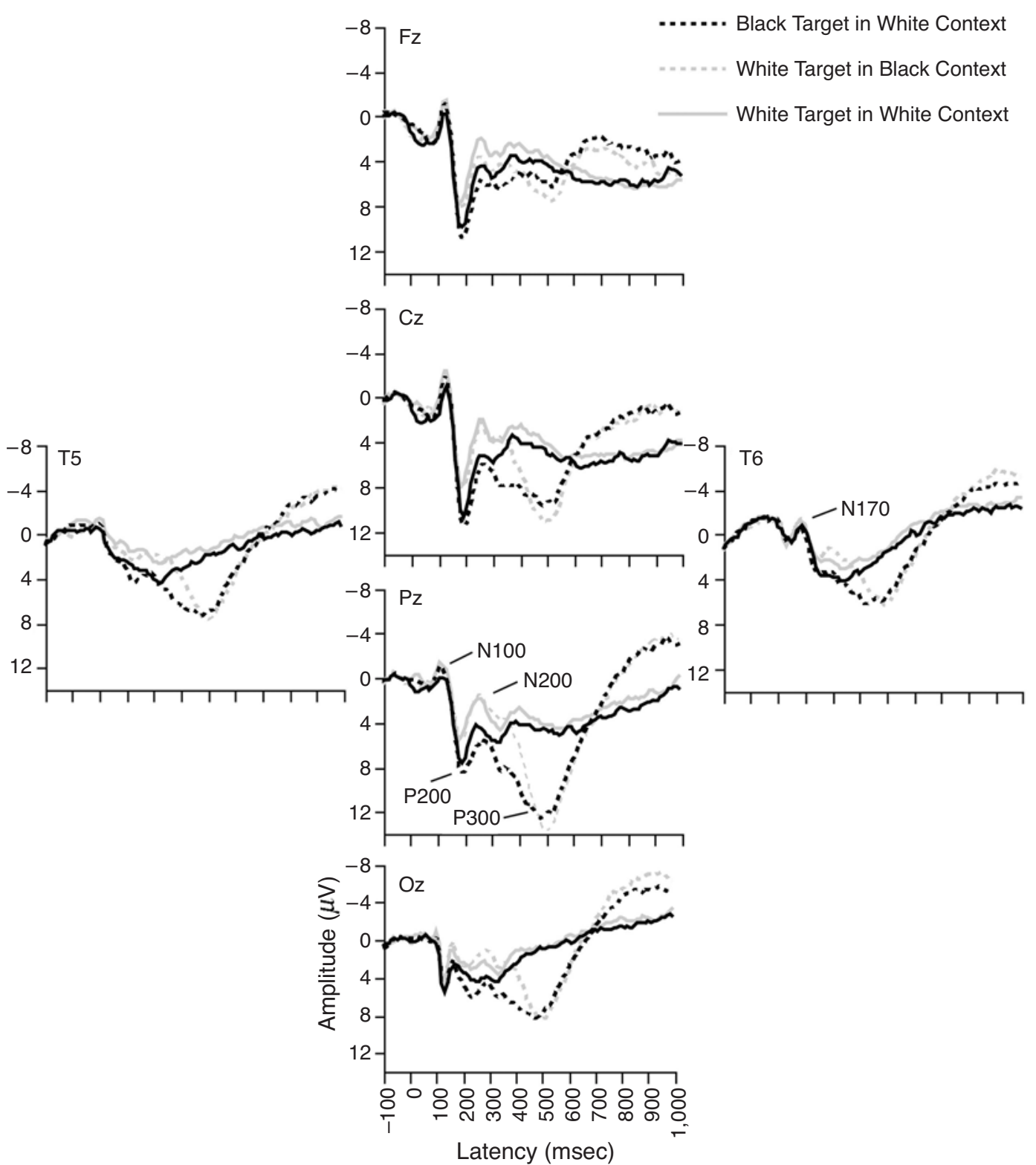

Figure 2. Grand average event-related potential waveforms from Phase 2 of Experiment 1 at selected sites as a function of target and context race. In Phase 2, all the participants performed the social categorization task. The N170, visible at temporal sites, is indicated at T6. The N100, P200, N200, and P300, visible at midline sites, are indicated at Pz.

\section{Materials}

Twenty pictures each of Black and White males were selected on the basis of normative attractiveness and race judgments obtained from an independent sample $(N=46)$. The stimuli selected were equated for attractiveness, and all had at least $80 \%$ agreement in race judgments. A white dot was placed on a randomly selected subset of pictures of each race in a random position. Following Macrae et al. (1997), the dot subtended $5^{\circ}$ of viewing angle. Ten different vegetable names were selected for the individuation task: asparagus, broccoli, carrots, cauliflower, celery, cucumber, eggplant, lettuce, radish, and spinach.

\section{Procedure}

The participants viewed the stimuli in two phases. In the first phase of the experiment, the vegetable task participants were told to judge whether a subsequently presented person liked the indicated vegetable, whereas the dot task participants were told to look for the presence of a dot on each picture. Each face was preceded by a randomly selected vegetable name that appeared on the screen for $1,000 \mathrm{msec}$. This was done for the participants in both the vegetable and the dot task conditions, so that stimulus presentation would be identical across participants. In addition, regardless of task, $10 \%$ of the faces had dots on them. Relevant judgments were 
registered via an appropriately labeled keypad after face offset (order of response labels varied across participants). In Phase 2, the faces were viewed again, with all the participants performing a race categorization task by indicating whether each person was Black or White. Stimulus presentation was identical to that in Phase 1 (i.e., dots and vegetable names were present). The explicit social categorization task was always performed last, to avoid sensitizing the participants to race information before they performed the vegetable or the dot task.

Although the P300 was not of primary interest here, we replicated the oddball trial structure of Ito and Urland (2003) that allowed for maximal assessment of the P300, thereby allowing us to make direct comparisons with those prior results (see also Mouchetant-Rostaing $\&$ Giard, 2003; Mouchetant-Rostaing et al., 2000). The oddball procedure involved the presentation of stimuli from a single category on the majority of trials within a block. To limit the number of trials, only faces of Blacks and Whites without dots served as the frequently presented context, or standard, stimuli. In each phase of the experiment, then, one block of trials showed primarily Black faces without dots, and the other block showed primarily White faces without dots (order counterbalanced across participants). Pictures were shown to the participants in sequences of five. Within each sequence, at least four faces came from the context category for that block. Embedded in both contexts were four types of targets from which ERP data were analyzed: Black males without dots, White males without dots, Black males with dots, and White males with dots. This resulted in the presentation of eight total types of trials in each phase of the experiment ( 2 types of context $\times 4$ types of targets). The target stimuli randomly appeared in the third, fourth, or fifth position in a sequence. Each face was shown for $1,000 \mathrm{msec}$, with a $1,200-\mathrm{msec}$ interstimulus interval before presentation of the next vegetable name. The word pause was shown on the screen after the fifth picture in the sequence until the participants pressed a button to initiate presentation of the next sequence of pictures. For each phase, the participants viewed 160 total trials ( 20 of each trial type), resulting in 320 total trials for the study.

\section{Psychophysiological data collection and reduction}

ERP data were recorded from F3, Fz, F4, C3, Cz, C4, P3, Pz, P4, $\mathrm{O} 1, \mathrm{Oz}, \mathrm{O} 2, \mathrm{~T} 5$, and $\mathrm{T} 6$, using tin electrodes sewn into an elastic cap (Electro-Cap International, Eaton, $\mathrm{OH}$ ). Miniature tin electrodes were also placed over the left and right mastoids. Active scalp sites were referenced on line to the left mastoid. ${ }^{2}$ Additional miniature tin electrodes were placed above and below the left eye and on the outer canthus of each eye to monitor vertical and horizontal eye movements, respectively. Electrode impedances were below $5 \mathrm{~K} \Omega$ at all sites. ERP recordings were amplified with a gain of 500 by NeuroScan Synamps model amplifiers (Compumedics, El Paso, TX) with a bandpass of $0.1-30 \mathrm{~Hz}$ (12-dB roll-off) and were digitized at $1000 \mathrm{~Hz}$. Data recording began $100 \mathrm{msec}$ before picture onset and continued throughout the 1,000 -msec picture presentation.

Off line, the data were rereferenced to a computed average of the left and right mastoids and were submitted to a regression procedure to remove the effects of vertical eye movements from the ERP (Semlitsch, Anderer, Schuster, \& Presslich, 1986), then corrected to the mean voltage of the $100-\mathrm{msec}$ prestimulus recording period. We next visually inspected the ERP data and deleted any trials with remaining ocular or other artifacts (e.g., due to movement). Data from all the sites for that trial were eliminated from further analysis if an artifact was detected at any of the scalp sites.

Figures 1 and 2 present grand average waveforms as a function of target and context race at a subset of electrodes during performance of either the vegetable and dot tasks (Phase 1) or the social categorization task (Phase 2), respectively. Four distinct deflections in the waveform that replicated the time course and morphology found in Ito and Urland (2003) can be seen at midline sites: a negative-going deflection with a mean amplitude of $128 \mathrm{msec}$, a positive-going deflection with a mean amplitude of $190 \mathrm{msec}$, a negative-going deflection with a mean amplitude of $259 \mathrm{msec}$, and a positive-going deflection with a mean amplitude of $520 \mathrm{msec}$. We refer to these components on the basis of their polarity and latency as the N100, P200, N200, and P300, respectively. ${ }^{3}$ The amplitude of each of the four components was quantified at each electrode by locating, within each participant's condition averages, the largest negativegoing potentials between 50 and $150 \mathrm{msec}$ and between 200 and $350 \mathrm{msec}$ after stimulus onset and the largest positive-going potentials between 150 and $250 \mathrm{msec}$ and between 350 and $900 \mathrm{msec}$ after stimulus onset (cf. Ito \& Cacioppo, 2000; Ito \& Urland, 2003). In addition, an N170 with a mean latency of $171 \mathrm{msec}$ was visible at lateral temporal sites. It was scored at temporal-parietal sites as the largest negative-going potential between 120 and $220 \mathrm{msec}$. Initial analyses on component latency revealed no effects of task or target race; therefore, only amplitude analyses will be presented.

\section{Analytic Strategy}

To examine the effects of attentional manipulations on the processing of social category information, components known to index explicit attention to race were examined. Preliminary analyses on the N100, P200, N200, and P300 revealed similar effects of experimental conditions at midline and left- and right-lateralized scalp sites. For brevity, we therefore will present results at the midline scalp site at which the component was maximal: $\mathrm{Cz}$ for N100 and N200, Pz for P200 and P300. Each component was analyzed with separate 2 (context race: Black or White) $\times 2$ (target race: Black or White) $\times 2$ (dot on target: present or absent) $\times 2$ (Phase 1 task: dot or vegetable) $\times 2$ (phase: Phase 1 , comprising the non-socialcategorization task, vs. Phase 2 , comprising the social categorization task) $\times 2$ (participant gender) mixed model analyses of variance (ANOVAs).

The N170 was analyzed with the same model, adding only a twolevel laterality factor (T5 or T6).

\section{Results \\ Effects of Target Race and Task on Components Previously Associated With Social Categorization}

N100. There was a marginal effect of target race on the N100, with larger responses to Whites $(M=-3.60 \mu \mathrm{V})$ than to Blacks $[M=-3.00 \mu \mathrm{V} ; F(1,26)=3.74, p=$ .07]. Note that this effect is opposite in direction to the findings from the two experiments in Ito and Urland (2003). Because of this reversal, the N100 was examined separately within each task. Analysis of the simple effects within each task for just Phase 1 reveals that this target race effect was significant for the participants in the dot task condition $[F(1,13)=10.91, p<.01]$, whereas the participants in the vegetable task condition showed no evidence of a target race effect $(F<1)$.

Looking just at Phase 2, when all the participants were performing the racial categorization task, the target race main effect was present only for the participants who had completed the dot task in Phase $1[F(1,26)=6.64, p<$ $.03]$, and again, N100s were more negative for Whites $(M=-4.85 \mu \mathrm{V})$ than for Blacks $(M=-4.65 \mu \mathrm{V})$. There was no target race effect during the social categorization task for individuals who completed the vegetable task in Phase $1(F<1)$.

P200. Despite the reversal in the N100, we replicated P200 effects from Ito and Urland (2003), with larger P200s to Blacks $(M=12.19 \mu \mathrm{V})$ than to Whites $[M=9.59 \mu \mathrm{V}$; $F(1,26)=36.74, p<.0001]$ (see Figures 1 and 2 ). 
Table 1

Mean P300 Amplitude by Target Race, Context Race, Phase, and Phase 1 Task for Experiment 1

\begin{tabular}{|c|c|c|c|c|c|c|c|c|}
\hline \multirow{3}{*}{$\begin{array}{l}\text { Context } \\
\text { Race }\end{array}$} & \multicolumn{4}{|c|}{$\begin{array}{c}\text { Phase } 1 \\
\text { (Dot or Vegetable Task) }\end{array}$} & \multicolumn{4}{|c|}{$\begin{array}{c}\text { Phase } 2 \\
\text { (Social Categorization Task) }\end{array}$} \\
\hline & \multicolumn{2}{|c|}{ Black } & \multicolumn{2}{|c|}{ White } & \multicolumn{2}{|c|}{ Black } & \multicolumn{2}{|c|}{ White } \\
\hline & $M$ & $S D$ & $M$ & $S D$ & $M$ & $S D$ & $M$ & $S D$ \\
\hline \multicolumn{9}{|c|}{ Dot Task Participants } \\
\hline Black & 11.21 & 4.59 & 12.27 & 4.87 & 9.14 & 4.09 & 15.86 & 4.98 \\
\hline White & 14.27 & 3.80 & 11.18 & 5.22 & 15.08 & 5.93 & 8.34 & 3.70 \\
\hline \multicolumn{9}{|c|}{ Vegetable Task Participants } \\
\hline Black & 9.55 & 4.30 & 11.73 & 3.81 & 7.85 & 4.96 & 17.89 & 6.56 \\
\hline White & 11.35 & 5.19 & 8.50 & 5.20 & 16.30 & 5.97 & 7.48 & 4.29 \\
\hline
\end{tabular}

Note-All values are in $\mu \mathrm{V}$. Boldface values show the target that is consistent with the race of the context pictures.

Target race also interacted with phase and dot presence $[F(1,26)=9.38, p<.01]$. Follow-up analyses showed that in all the phases, and for both dotted and undotted stimuli, P200s were larger to Blacks than to Whites. However, when the pictures had dots on them, the effect was larger in Phase 2 (when the participants were performing the social categorization task), as compared with Phase $1[F(1,26)=5.90, p<.05]$. For the pictures without dots, the magnitude of the target race effect did not differ between the two phases $(F<1)$. This pattern of results suggests that when a face is processed in the presence of a distracting visual stimulus (the dot), attention to race is attenuated when a task is performed that does not explicitly focus on social category membership (either the dot or the vegetable task). However, it is important to note that the effect is only attenuated and not eliminated. Even with the perceptual distraction of the dots and the processing distraction of looking for dots or thinking about vegetable preferences, target race still modulated the P200.

There was also a significant context race $\times$ target race interaction $[F(1,26)=6.9, p<.05]$, so that $\mathrm{P} 200$ s were bigger when the target race was different from the context race $(M=11.38 \mu \mathrm{V})$ than when the target race was the same as the context race $(M=10.38 \mu \mathrm{V})$. This interaction was qualified by a significant context race $X$ target race $X$ Phase 1 task $\times$ dot interaction $[F(1,26)=4.99, p<.05]$. Simple effects tests indicated that the context race $\times$ target race effect was significant only for the participants who performed the vegetable task first, and only when they were viewing targets that did not have dots on them. This effect indicates that sensitivity to the relation between target and context race occurred only when distraction from the dots was minimal-that is, only when the faces lacked the dot stimulus and only for those participants for whom the dots were not task relevant.

N200. Across multiple studies and different processing tasks, the N200 has shown larger responses to Whites than to Blacks (Ito et al., 2004; Ito \& Urland, 2003). We replicated this here. N200s were more negative-going for pictures of Whites $(M=-0.35 \mu \mathrm{V})$ than for pictures of
Blacks $[M=2.27 \mu \mathrm{V} ; F(1,26)=55.23, p<.0001]($ see Figures 1 and 2). ${ }^{4}$

P300. The P300 had previously been sensitive to the social relationship between the target and the context (Ito \& Urland, 2003). This effect was replicated, as can be seen in a significant target race $\times$ context race interaction $[F(1,26)=137.00, p<.0001]$. The $\mathrm{P} 300$ was larger when the target's race differed from $(M=14.34 \mu \mathrm{V})$, rather than matched $(M=9.16 \mu \mathrm{V})$ the context.

The effect was also moderated by phase $[F(1,26)=$ $45.33, p<.0001]$. The pattern above was stronger when the task explicitly involved social categorization than when it dealt with vegetable judgments or dot perception. Importantly, though, examination of the simple effects within phase revealed that the target race $\times$ context race interaction was significant both when the vegetable or the dot task and when the racial categorization task were performed $[F \mathrm{~s}(1,26)=27.43$ and 114.46 , respectively, $p<.001$; see Table 1]. Thus, although social category information had a smaller effect on working memory processes during the non-social-categorization task, the participants still showed social category effects during processing that directed attention away from the social category or away from the face entirely (see also Ito \& Cacioppo, 2000; Ito \& Urland, 2003). ${ }^{5}$

\section{Effects of Target Race and Task on the N170}

The N170 was larger at $\mathrm{T} 6(M=-3.23 \mu \mathrm{V})$ than at T5 $[M=-1.04 \mu \mathrm{V} ; F(1,25)=15.90, p<.001]$. Contrary to previous research, N170s differed as a function of race, with larger N170s to Whites $(M=-2.44 \mu \mathrm{V})$ than to Blacks $[M=-1.84 \mu \mathrm{V} ; F(1,25)=6.95, p<$ $.05]$. This interacted with laterality, showing that the race difference occurred at T5 $\left[M_{\text {White }}=-1.46 \mu \mathrm{V}\right.$ and $\left.M_{\text {Black }}=-0.62 \mu \mathrm{V} ; F(1,25)=8.33, p<.01\right]$, but not at T6 $\left[M_{\text {White }}=-3.41 \mu \mathrm{V}\right.$ and $M_{\text {Black }}=-3.10 \mu \mathrm{V}$; $F(1,25)=2.40]$ (see Figures 1 and 2). Target race also interacted with phase. N170s did not differ to Whites $(M=-2.20 \mu \mathrm{V})$ and to Blacks $(M=-2.10 \mu \mathrm{V})$ in the first phase of the experiment, in which the participants were performing either the vegetable or the dot task. 


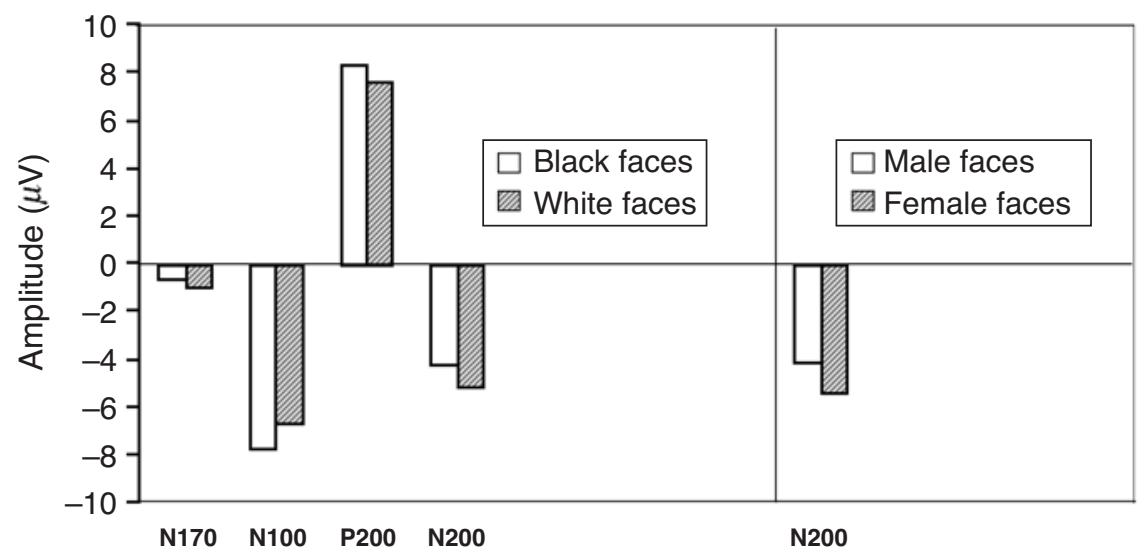

Figure 3. Mean N170, N100, P200, and N200 amplitudes as a function of target race (left panel) and mean $\mathbf{N 2 0 0}$ amplitudes as a function of target gender (right panel) in Experiment 2.

During the second phase, when all the participants were performing a racial categorization task, N170s were larger to Whites $(M=-2.67 \mu \mathrm{V})$ than to Blacks $[M=$ $-1.60 \mu \mathrm{V} ; F(1,25)=13.27, p<.001]$.

\section{Discussion}

Although the participants performed tasks in the first phase of the experiment that encouraged them to process faces at either a deeper (the vegetable task) or a more shallow (the dot task) level than racial category, electrocortical responses at midline sites were similar to when the participants were simply processing individuals in terms of their race in Phase 2 (see also Ito \& Urland, 2003). Regardless of task, target race modulated ERP responses by $190 \mathrm{msec}$, as is shown by larger P200s to Blacks. Replicating past research, N200s were larger to Whites than to Blacks. Although P300 effects were stronger when race was explicitly attended to, all the tasks, nevertheless, produced the same pattern of P300 responses: P300s were larger to targets whose race differed from the race of preceding faces.

Interestingly, N100 responses were not consistent across conditions and did not replicate the results in Ito and Urland (2003). Instead, the previously obtained pattern of larger N100s to Blacks was reversed for the participants who performed the dot task in Phase 1, and this occurred both when they were attending to dots (Phase 1) and when they were attending to race (Phase 2). The dots that the participants were instructed to detect were white in color. The larger N100s elicited by White faces may reflect an unintended effect of these participants' vigilant search for round white objects, which then also carried over into the racial categorization task. This leaves unexplained the absence of N100 differences for the participants in the vegetable task condition when they were performing either the vegetable or the racial categorization task. The presence of task-irrelevant but, nevertheless, salient dots on some of the stimuli and/or the preceding presentation of an initially task-relevant vegetable name on every trial may have constituted an attentional load manipulation reducing visual attention to race cues (cf. Rees \& Lavie, 2001).

Unlike in past research, we also obtained target race effects in the N170. As is predicted by a general expertise explanation, N170s were larger toward the social group with which the participants were likely to have had more experience, but only in Phase 2 of the experiment. In past studies in which the N170/VPP was insensitive to race, participants were attending to other stimulus dimensions (e.g., counting butterflies or making evaluative judgments; Caldara et al., 2003; Ito et al., 2004; but see Caldara et al., 2004). Similarly, N170s to Whites and Blacks did not vary in Experiment 1 when a non-social-categorization task was performed, but did when race was attended to. A social categorization goal might, therefore, be necessary, or something about the repeated viewing of the stimuli under different task conditions might be important. This will be explored further in Experiment 2.

In sum, these results show that racial cues can affect the P200, N200, and P300 even with the direction of attention to deeper and more shallow levels of analysis, whereas N170 effects occur only during the social categorization task. In the N100, the processing goals had an effect not only when the individuation or the featuredetection task was explicitly performed (Phase 1), but also when the participants switched to explicitly attending to race in Phase 2. This pattern raises the possibility that stimulus features, which remained constant between the two phases of the experiment, contributed to the differences in N100 effects, relative to past research. In past research in which N100 race effects were obtained, only faces were shown (Ito \& Urland, 2003), whereas in Experiment 1 , all the faces in both phases were preceded by vegetable names, and some had dots on them.

\section{EXPERIMENT 2}

Experiment 2 was designed to explore the degree to which stimulus complexity produced the changes in N100 results and the influence of phase versus task on 
N170 race effects. This necessitated several procedural changes. Experiment 2 contained only one phase of data collection and directly replicated the stimulus presentation of Ito and Urland (2003), so that any departure from prior results would be due to task and not to stimulus factors. We also included stimuli that varied in gender, as well as race, to allow an examination of processing goals on both category dimensions. Because the visual feature detection task required extraneous objects on the stimuli, we omitted that task and focused only on the effects of a deeper level of processing. To implement a more individuating task that did not require an alteration to the stimulus presentation, we had the participants judge whether each person was introverted or extroverted.

\section{Method}

\section{Participants}

Twenty-two students (11 females) from the University of Colorado participated for partial fulfillment of class requirements. One male and 1 female identified their race as Asian American, and the remaining identified themselves as White.

\section{Materials}

In addition to the 40 pictures of Black and White males from Experiment 1,20 additional pictures each of Black and White females were selected on the basis of the same criteria as those in Experiment 1 . We reasoned that smiling might influence introversion/ extroversion judgments but, in meeting other constraints, were unable to select photos of people all of whom were either smiling or not smiling. As a result, both types of pictures were used, but we ensured that their distribution did not differ among the four categories of pictures.

\section{Procedure}

The participants were told that the experiment was on first impressions and were asked to judge whether people were generally introverted and shy or extroverted and outgoing on the basis of their visual appearance. Stimulus presentation and construction of trials (e.g., showing faces in five-picture sequences) were identical to those in Experiment 1. With the four types of faces being viewed, the participants completed four blocks of trials, with the majority of the faces coming from a different category within each block (e.g., White males). Within some sequences of five faces, all the faces came from this context category. In other sequences, one of the faces came from one of the other categories (e.g., Black male, Black female, or White female). Block order was counterbalanced across participants. Personality judgments were registered via an

\section{Black Male Context}

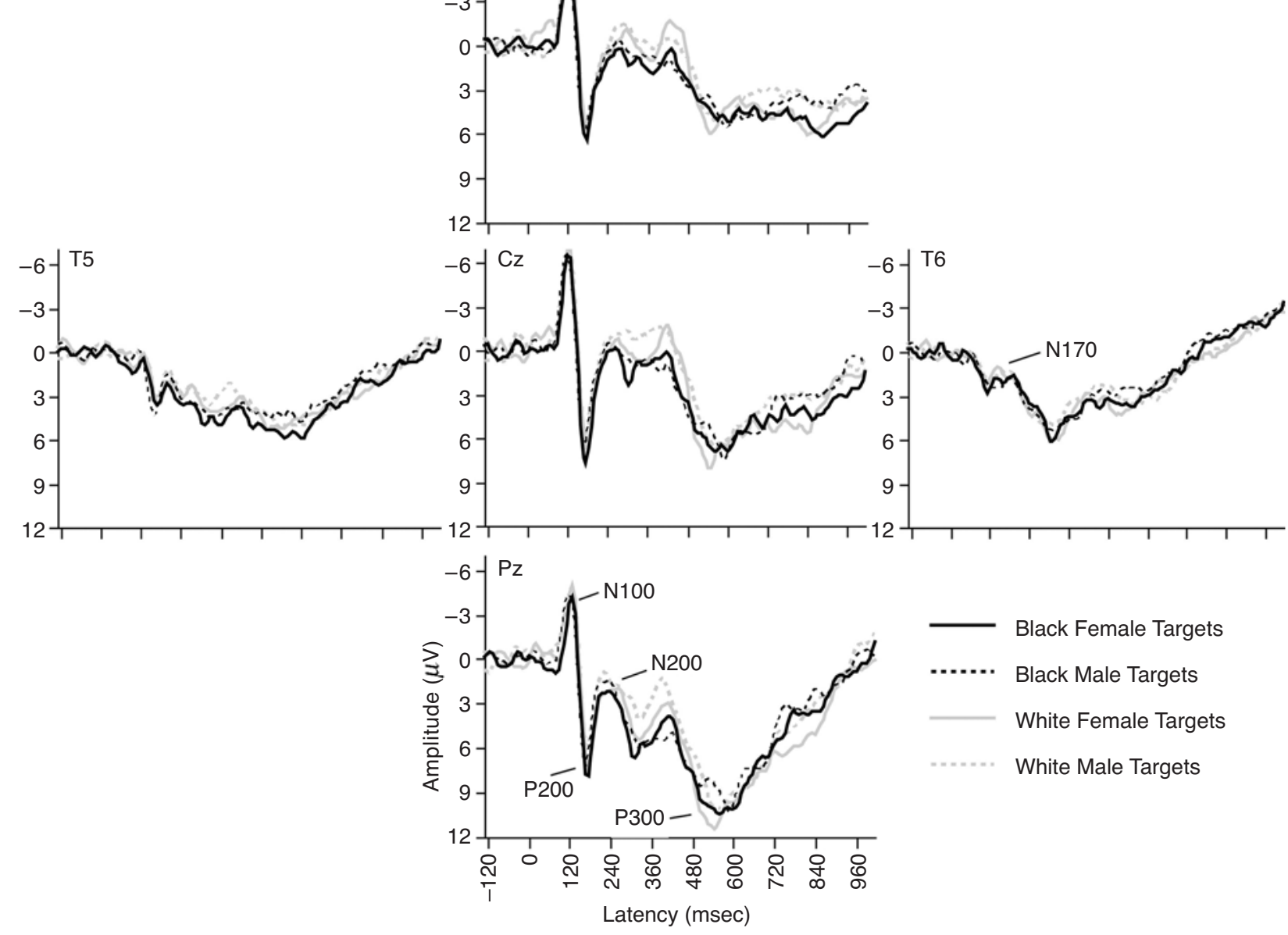

Figure 4. Grand average event-related potential waveforms from Experiment 2 at selected sites as a function of target race and gender when the faces were seen in a context of Black male faces. The N170, visible at temporal sites, is indicated at T6. The N100, P200, N200, and P300, visible at midline sites, are indicated at Pz. 


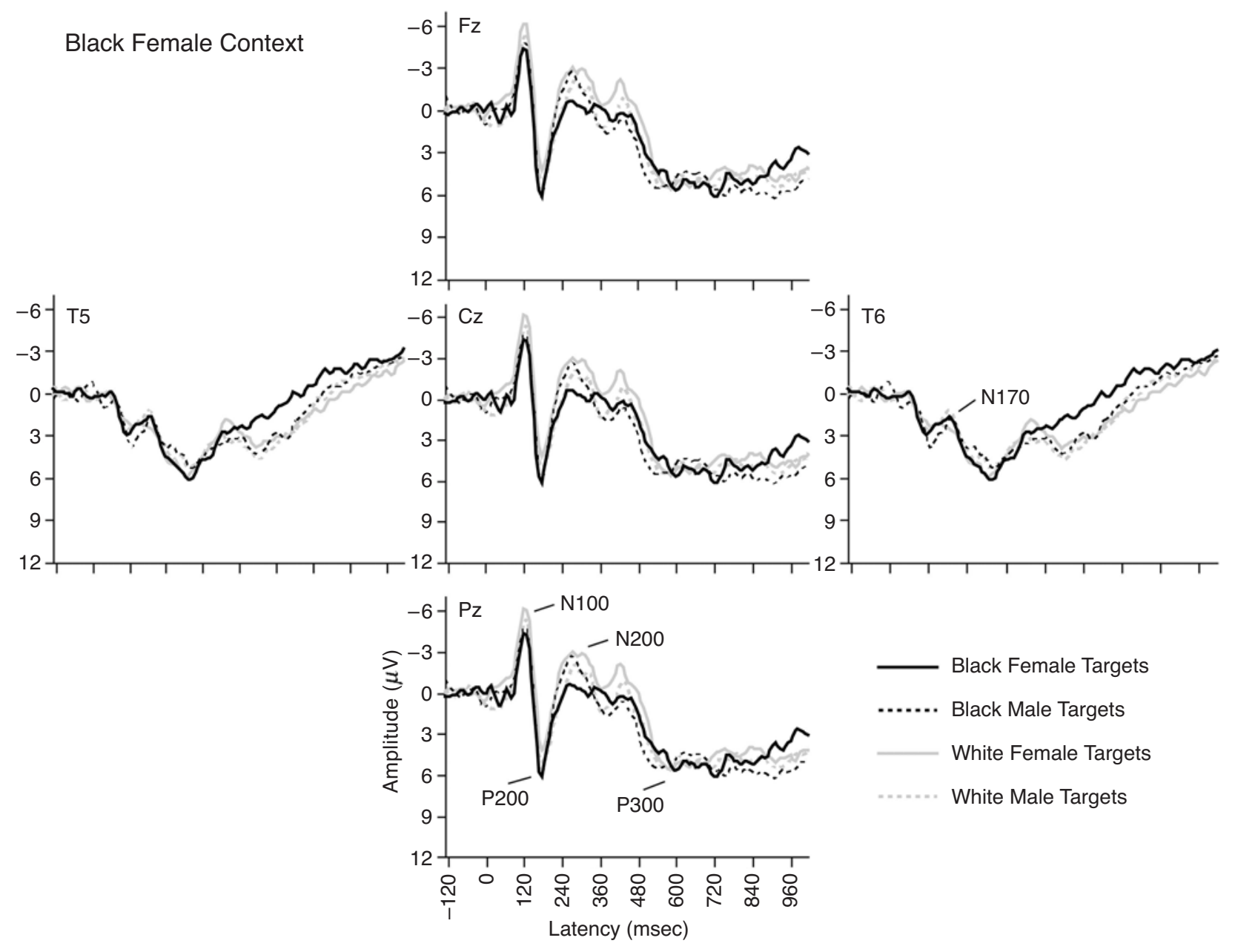

Figure 5. Grand average event-related potential waveforms from Experiment 2 at selected sites as a function of target race and gender when the faces were seen in a context of Black female faces. The N170, visible at temporal sites, is indicated at T6. The N100, P200, N200, and P300, visible at midline sites, are indicated at Pz.

appropriately labeled keypad, with mapping of response labels to buttons counterbalanced across participants. The participants viewed 20 sequences of each context race and gender by target race and gender combination, which resulted in 320 total trials.

ERP data acquisition and reduction were identical to those in Experiment 1 , except that epoch lengths of -128 to $1,024 \mathrm{msec}$ were used and data were not available from occipital electrodes. Component amplitudes were quantified as in Experiment 1. Figures 4-7 show waveforms as a function of target race and gender at a subset of electrodes. Each figure shows responses to the four types of targets embedded in a different context (e.g., Black males in Figure 4). As can be seen, an N100 (mean latency of $120 \mathrm{msec}$ ), a P200 (178 msec), an N200 (257 msec), and a P300 (560 msec) are visible along midline electrodes, and the N170 $(176 \mathrm{msec})$ is seen at temporal leads with mean latencies similar to those in Experiment 1 .

\section{Analytic Strategy}

The statistical models examined in Experiment 2 followed those in Experiment 1, with the addition of two factors that account for the addition of female targets: context gender (male or female) and target gender (male or female).

\section{Results}

\section{Effects of Target Race and Gender on}

Components Previously Associated With

Social Categorization

N100. Despite the direction of attention to an individuating judgment, with the simpler stimulus presentation in Experiment 2, we replicated the effects of Ito and Urland (2003). N100s were larger to pictures of Blacks $(M=$ $-7.74 \mu \mathrm{V})$ than to Whites $[M=-6.63 \mu \mathrm{V} ; F(1,21)=$ $15.52, p<.005]$. The race main effect means can seen in Figure 3, and the relevant waveforms are shown in Figures 4-7.

P200. As in the N100, and replicating the results in Experiment 1 and Ito and Urland (2003), the P200 also showed a main effect of target race $[F(1,21)=7.20, p<$ $.05]$, with larger responses to Blacks $(M=8.31 \mu \mathrm{V})$ than to Whites $(M=7.61 \mu \mathrm{V}$; Figures 3-7). In Ito and Urland, effects of target gender also began to emerge in the P200. Consistent with this, there was a context gender $\times$ 


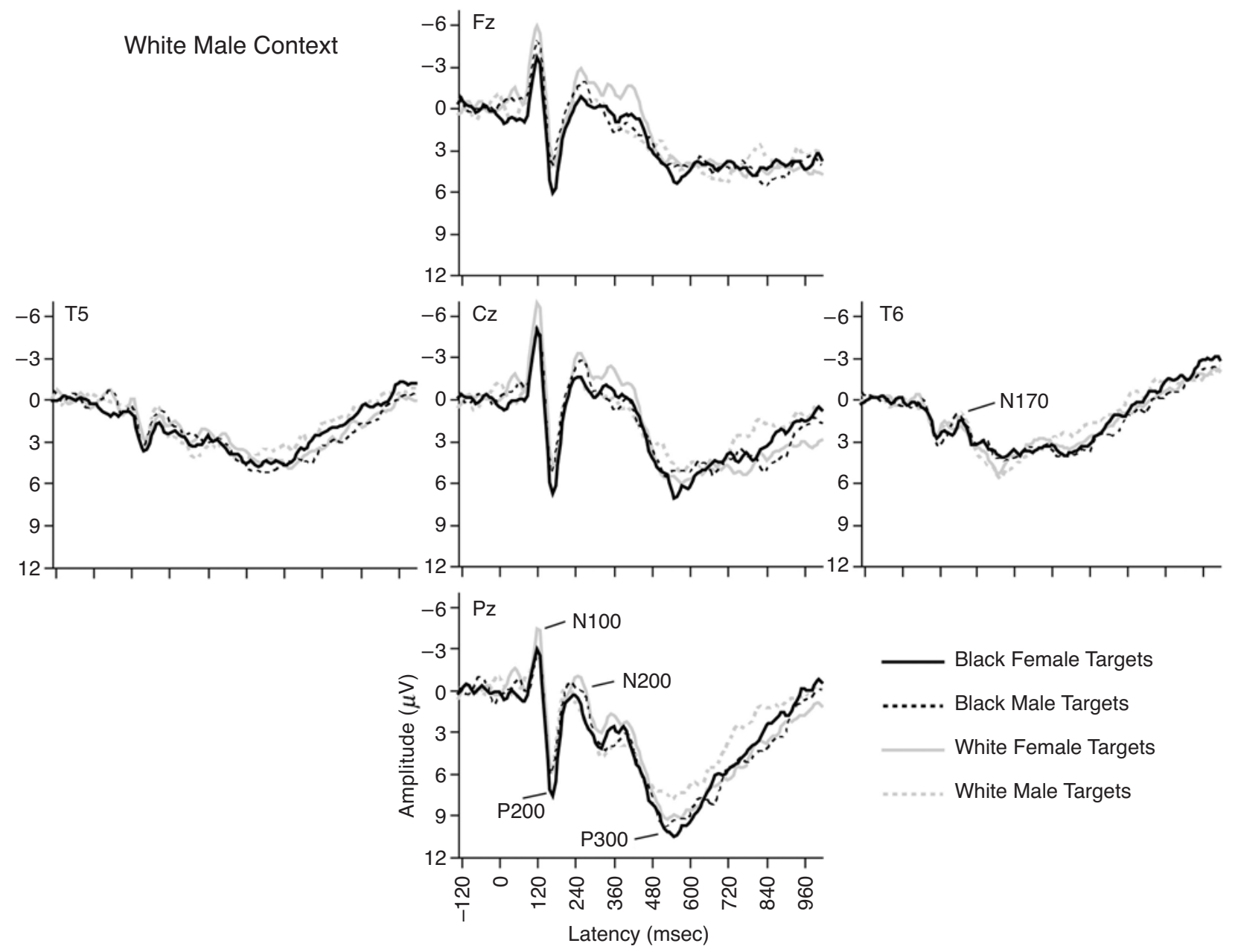

Figure 6. Grand average event-related potential waveforms from Experiment 2 at selected sites as a function of target race and gender when the faces were seen in a context of White male faces. The N170, visible at temporal sites, is indicated at T6. The N100, P200, $\mathbf{N 2 0 0}$, and P300, visible at midline sites, are indicated at Pz.

target gender interaction $[F(1,21)=6.49, p<.05]$. P200s were larger to targets whose gender differed from the gender in the preceding context (i.e., responses were larger to females seen in the context of males and to males seen in the context of females). This effect was also qualified by a marginally significant context gender $\times$ target gender $\times$ target race interaction $[F(1,21)=$ $4.05, p=.057]$. The three-way interaction revealed that the larger responses to Blacks than to Whites were obtained when there was an inconsistency between target and context gender. That is, when males were viewed in a context of females, P200s to Black males $(M=$ $9.02 \mu \mathrm{V})$ exceeded $\mathrm{P} 200$ s to White males $[M=7.70 \mu \mathrm{V}$; $F(1,21)=4.86) p<.05]$. When females were viewed in a context of males, P200s to Black females $(M=$ $8.96 \mu \mathrm{V})$ exceeded those to White females $[M=$ $7.55 \mu \mathrm{V} ; F(1,21)=8.75, p<.01] .^{6}$

N200. As in Experiment 1 and past research (Ito et al., 2004; Ito \& Urland, 2003), N200s were larger to Whites $(M=-5.20 \mu \mathrm{V})$ than to Blacks $[M=-4.23 \mu \mathrm{V}$;
$F(1,21)=10.26, p<.005]$. Ito and Urland also found a target gender main effect, which we replicated here $[F(1,21)=8.79, p<.01]$. N200s were larger to females $(M=-5.34 \mu \mathrm{V})$ than to males $(M=-4.08 \mu \mathrm{V}$; Figures 3-7).

There was also a marginally significant context race $\times$ context gender $\times$ target race $\times$ target gender interaction $[F(1,21)=4.10, p=.056]$. Consistent with the two main effects, simple effects tests showed larger N200s to targets that were either White or female in all the contexts except the White male context. Said differently, N200s were larger to Black females, White females, and White males than to Black males in the Black female context, the Black male context, and the White female context $[F \mathrm{~s}(1,21)=5.93,13.15$, and 12.41 , respectively; $p \mathrm{~s}<.05]$. In the White male context, N200s to Black males were equally large as responses to the other three types of targets $(F<2)$. Thus, although N200s were generally larger to Whites and to females, this effect was attenuated when Black males were seen in 
Table 2

Mean P300 Amplitude by Target Race and Context Race and Gender for Experiment 2

Target Race and Gender

\begin{tabular}{|c|c|c|c|c|c|c|c|c|c|}
\hline \multirow[b]{2}{*}{ Context } & \multicolumn{2}{|c|}{ Black Female } & \multicolumn{2}{|c|}{ Black Male } & \multicolumn{2}{|c|}{ White Female } & \multicolumn{2}{|c|}{ White Male } & \multirow[b]{2}{*}{$F$} \\
\hline & $M$ & $S D$ & $M$ & $S D$ & $M$ & $S D$ & $M$ & $S D$ & \\
\hline & & 74 & 11.81 & 4 & 11.47 & 4 & 11. & 4.05 & $2.98^{*}$ \\
\hline & & $T$ & & 3. & 12 & & 11. & 3.73 & 2.30 \\
\hline & 1 & 4.66 & 11 & 4.44 & 4 & 3.91 & 10.83 & 4.03 & $5.40^{*}$ \\
\hline White $\mathrm{m}$ & 12.17 & 4.52 & 11.21 & 6.30 & 11.87 & 4.27 & 9.41 & 4.11 & $12.16^{* *}$ \\
\hline
\end{tabular}

Note-All values are in $\mu \mathrm{V}$. Within each row, boldface values show the target that is consistent with context in both race and gender. The $F$ values represent a comparison of the boldface target with the other three types of targets within each context. $D f=1$ and $21 .{ }^{*} p<.05 .{ }^{* *} p<.005$.

the context of White males. As was noted earlier, the P300 is typically sensitive to a target's category membership, relative to its surrounding context, resulting in larger responses when a target differs from the preceding context. The failure of N200s to Black males to differ from responses to other targets in the White male context may reflect a similar process. The inconsistency between target and context race appears to have increased the N200 to Black males in this context, relative to the responses seen in other contexts.

P300. In accord with the P300's prior sensitivity to working memory, which typically results in interactions between a target's category membership relative to its surrounding context, the two-way context race $\times$ target race and context gender $\times$ target gender interactions were significant $\left[F_{\mathrm{S}}(1,21)=13.75\right.$ and 12.12 , respectively; $p \mathrm{~s}<.005]$. Both were qualified by the four-way context race $\times$ context gender $\times$ target race $\times$ target gender interaction $[F(1,21)=7.77, p<.05$; Figures 4-7]. Simple effects tests showed larger responses to targets that were inconsistent with context pictures along either race or gender for each context except Black males (see Table 2). That is, with a context of Black females, P300s were smaller to Black female than to Black male, White female, and White male targets. With a context of White males, P300s were smaller to White male targets than to the other three types of targets, and with a context of White females, P300s were smaller to White female targets than to the other three types of targets. With a context of Black males, however, P300s to Black males were equal to those to the other three types of targets.

\section{Effects of Target Race and Gender on the N170}

N170s did not vary between T5 and T6 $(F<2)$, but as in Experiment 1, the $\mathrm{N} 170$ was larger to Whites $(M=$ $-1.01 \mu \mathrm{V})$ than to Blacks $[M=-0.60 \mu \mathrm{V} ; F(1,21)=$ 12.64, $p<.0005$; see Figures 3-7]. There was also a main effect of context race. Regardless of the race or gender of the target face, N170s were larger when faces were seen in the context of Whites $(M=-1.07 \mu \mathrm{V})$ than in the context of Blacks $[M=-0.63 \mu \mathrm{V} ; F(1,21)=$ $4.67, p<.05]$. Although race affected the N170, there were no effects of target or context gender.

\section{Discussion}

In Experiment 1, simultaneous changes in processing goals and stimulus complexity, relative to past research (Ito \& Urland, 2003), resulted in changes to N100 responses but in a replication of the P200, N200, and P300 results. In Experiment 2, in which presentation parameters identical to those in past research were used and only the processing goal was varied, N100 race effects were obtained. Even when attention was focused away from social category by requiring a personality judgment, race modulated responses as early as $120 \mathrm{msec}$, with larger N100s to Blacks than to Whites. As in Ito and Urland, P200s, N200s, and P300s were also sensitive to race and gender. Moreover, we replicated the N170's sensitivity to target race during the performance of a more individuating task. This suggests that the absence of N170 race effects in Phase 1 of the prior experiment was due to stimulus complexity, rather than to task.

Although these effects largely replicate the results of past research, there were some higher order interactions in the N200 and P300. In both cases, the pattern of results indicate a different processing of Black males. In the N200, whereas responses were generally larger to Whites and females, N200s to Black males were as large as responses to targets who were White, female, or both, when seen in the context of White males. In the P300, responses to Black males in the Black male context were as large as the responses to targets who differed from the context in terms of race or gender. This suggests that whereas attentional processes reflected in the N200 generally favor Whites and females and working memory processes reflected in the $\mathrm{P} 300$ are generally sensitive to inconsistencies between a target and a context's social categories, Black males are a special category, attracting processing resources over and above these other effects. This is not surprising, given the cultural significance of Black males. They are a group associated with negative stereotypes, such as violence and aggression. Data from this same population further indicate that Blacks were a group with which the participants had had little contact (Ito et al., 2004). In a society where White males typically serve as a reference point (Stroessner, 1996), it is not surprising that Black males elicit special processing. 


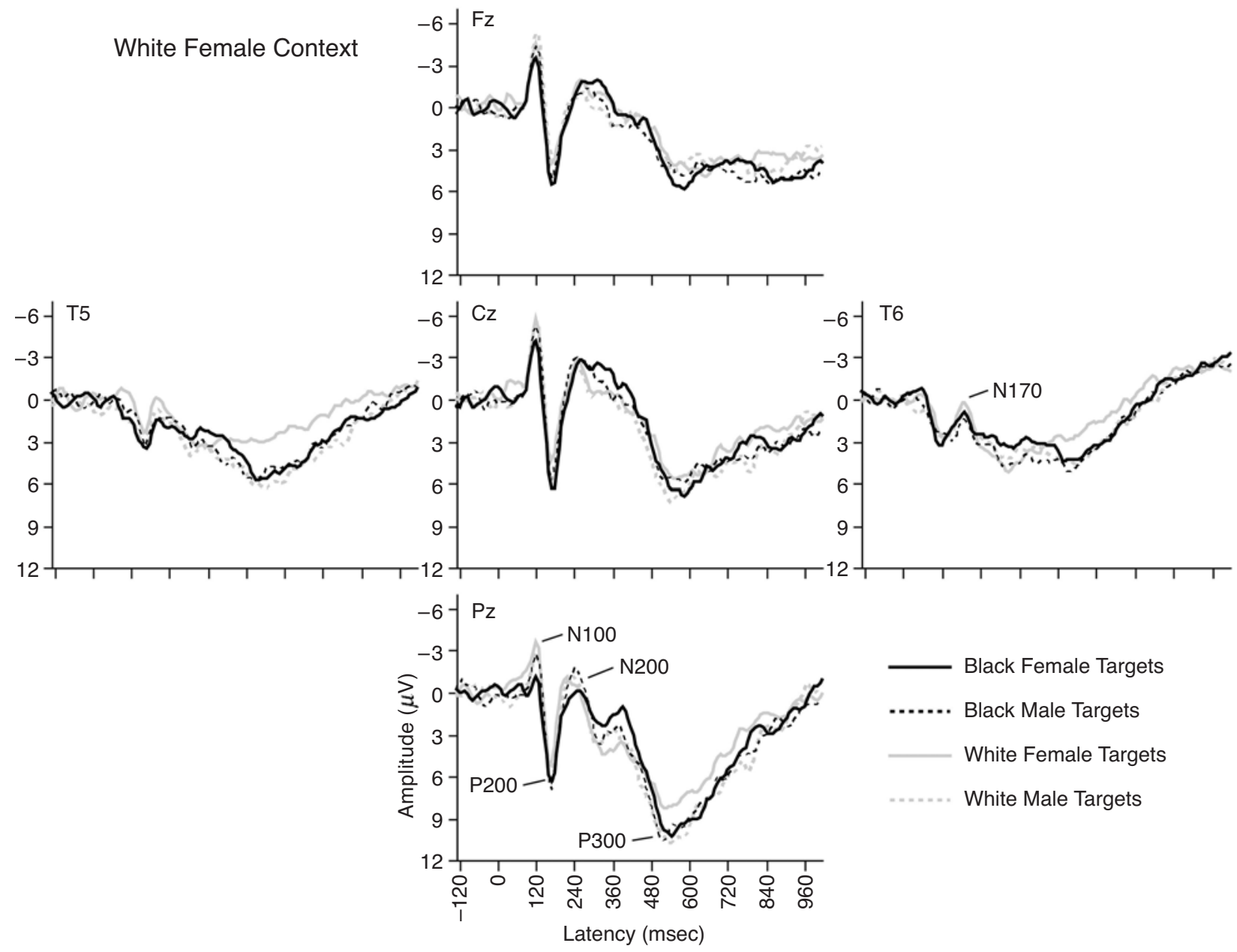

Figure 7. Grand average event-related potential waveforms from Experiment 2 at selected sites as a function of target race and gender when faces were seen in a context of White female faces. The N170, visible at temporal sites, is indicated at T6. The N100, P200, N200, and P300, visible at midline sites, are indicated at Pz.

Another departure from past results was in the P200 gender effects. In past studies, P200s have been larger to males than to females (Ito \& Urland, 2003). The interaction between context and target gender indicated that gender was clearly affecting processing in the P200, but we did not replicate the simple gender main effect. Thus, systematic differences in processing to males versus females was disrupted by the individuating task. At the same time, responses to females versus males did differentiate in the N200. The individuating task delayed but did not eliminate the differences in processing as a function of gender that have been seen in past research.

\section{GENERAL DISCUSSION}

Across two experiments, we found electrocortical evidence that mechanisms previously associated with the structural encoding of faces are sensitive to racial cues. This is seen in the larger N170s to Whites than to Blacks. N170s, however, were not sensitive to face gender. We also found evidence that attention to social category information occurs even under conditions known to attenuate stereotyping and prejudice. The processing of individuals while personal features other than social category were consciously attended to in the form of either vegetable preference (Experiment 1) or a personality trait (Experiment 2) or in terms of a low-level visual feature not associated with the social category (Experiment 1) resulted in midline ERP responses similar to those obtained when the participants were explicitly processing the faces in terms of race or gender (Phase 2 in Experiment 1; Ito \& Urland, 2003). This time course is consistent with other studies in which modulation was looked at as a function of gender and age categories (Mouchetant-Rostaing \& Giard, 2003; Mouchetant-Rostaing et al., 2000). Although it was not procedurally possible to directly examine the effects of the processing goals we used on the application of stereotypes and prejudice in these experiments, we have reason to suspect that they were successful. Individuating tasks similar to that used in Ex- 
periment 2 (see Fiske \& Neuberg, 1990) and the specific vegetable and dot tasks used in Experiment 1 have been shown to attenuate the activation of stereotype and prejudice in response to category exemplars in other studies (Macrae et al., 1997; Wheeler \& Fiske, 2005).

At the same time, the present results demonstrate that increases in visual complexity when paired with manipulations in processing goals may be sufficient to alter social category processing. In Experiment 1, in which different levels of processing were paired with the addition of salient visual information - the dots on some of the faces and the presentation of vegetable names-N100 responses differed from past research. Moreover, although race effects in the P200 and P300 in Experiment 1 were seen during all the tasks and replicated past research, they were attenuated during the dot and vegetable tasks. By contrast, in Experiment 2, an individuation goal performed when social targets were still the focal stimuli produced a pattern of $\mathrm{N} 100$ responses identical to that found when social categorization was the explicit task (Ito \& Urland, 2003). This suggests that stimulus complexity, more so than attentional focus, was responsible for the lack of N100 race effects in Experiment 1, a conclusion consistent with general decreases in visual attention to non-task-relevant features seen under conditions of perceptual load (Rees \& Lavie, 2001). At the same time, the individuating task in Experiment 1 (vegetable preference) was probably more novel than the individuating task in Experiment 2 (introversion-extroversion judgments), so it may have constituted a more effective attentional manipulation than the task in Experiment 2 did. If this is the case, attentional focus could modulate $\mathrm{N} 100$ responses to social category information under certain conditions. We also note that although stimulus complexity differed between the two experiments, we are not able to determine the relative importance of individual features on attention (i.e., dots on some of the faces vs. presence of vegetable names before each face).

\section{Implications for Face Processing}

Bruce and Young (1986) have argued that structural encoding and the processing of social category information (which they label visual semantic processing) are distinct, sequentially ordered stages, with social category processing depending on the representation constructed during structural encoding. However, the research of MouchetantRostaing and colleagues (Mouchetant-Rostaing \& Giard, 2003; Mouchetant-Rostaing et al., 2000), our past research (Ito \& Urland, 2003), and the present results (especially the N100 race effects in Experiment 2) suggest that social category processing need not depend on structural encoding. Social category effects can occur before $170 \mathrm{msec}$, the latency repeatedly associated with completion of structural encoding. This conclusion is also consistent with recent MEG research showing a facesensitive response before $170 \mathrm{msec}$ (Liu, Harris, \& Kanwisher, 2002). That response, labeled an M100, was particularly sensitive to face parts, whereas a response occurring at $170 \mathrm{msec}$, the M170, was more sensitive to face configuration. On the basis of this, the authors suggested that the structural encoding reflected in the N170 ERP and M170 MEG responses is more specific to processes related to recognition, whereas earlier processes reflected in the M100 are sensitive to individual facial features. The effects we obtained before $170 \mathrm{msec}$ that are sensitive to social category may reflect the latter process.

Given that the assumption of sequential structural encoding and social categorization seems inappropriate, we can also ask whether the assumption that they are distinct operations might also be inappropriate. The sensitivity of the N170 in both experiments to target race may indicate that structural encoding and social category perception can be performed by the same mechanism. Moreover, given interracial contact disparities that tend to involve greater experience in perceiving Whites than Blacks, especially among our mostly White participants, the larger N170s we obtained to Whites are consistent with a domain-general expertise view of the N170. These results, however, are inconsistent with four prior demonstrations in which the N170 or VPP did not vary by target race (Caldara et al., 2004; Caldara et al., 2003; Ito et al., 2004). It is important to note that three of those past studies showed faces in a heterogeneous context that included nonfaces. This invites the interpretation that when faces are perceived in a context homogeneous with respect to their basic-level distinction (face/nonface), the mechanism associated with structural encoding and indexed by the N170 can also be sensitive to features that differentiate among faces. It is the case that vegetable names and dots were also seen in Experiment 1, but N170 race effects did not occur in Phase 1, when these other stimuli were relevant. N170 race effects emerged only in Phase 2, when only faces were relevant. The absence of target gender N170 effects is also consistent with a social expertise explanation. Although perceivers may differ in the contact they have had with different racial groups either personally or through broader social learning mechanisms, it would be unusual for someone to have had large differences in the experience of perceiving men and women.

The only difficulty with this interpretation is in reconciling recent data from Caldara et al. (2004), who showed faces of Asians and Whites to White participants in a context homogeneous with respect to the basic-level category (i.e., only faces were seen). In this study, N170s did not differ as a function of target race. The number of unique faces used may have played a role. Whereas we used 40 of each category, Caldara et al. (2004) used 72. If we are correct that eliminating the need for basic-level distinctions can increase the sensitivity of processes indexed by the N170 to race, it is not surprising that this is more likely to occur under conditions that facilitate structural face encoding (i.e., viewing fewer faces).

In addition to the different effects of race and gender on the N170, Experiment 2 revealed earlier race (N100) than gender (P200) effects (see also Ito \& Urland, 2003). 
This category potency difference is not due to a confound with low-level visual features (e.g., that Black and White faces might differ in some nonsocial feature, such as luminance, more so than do male and female faces), because the effect is also obtained with grayscale images equated for luminance and contrast (Ito \& Urland, 2003). Instead, we think it reflects differences either in the social importance placed on the processing of race versus gender or in the structural salience of facial features used to make race versus gender distinctions.

\section{Attention to Race and Gender}

Amplitude increases in an anterior N200 have been consistently associated with the selection of attention on the basis of nonspatial cues (Eimer, 1997; Kenemans, Kok, \& Smulders, 1993; Näätänen \& Gaillard, 1983; Wijers, Mulder, Okita, Mulder, \& Scheffers, 1989). This has led to the association of covert orienting to relevant and/or salient features with N200 amplitude and the labeling of this component as the selection negativity. Although analogous labels have not been applied to N100 and P200 effects, these components also often increase as a function of attention to nonspatial cues (Czigler \& Geczy, 1996; Kenemans et al., 1993; Wijers et al., 1989). Our findings are, therefore, consistent with extant results on attentional selection and extend findings from the physical properties of objects made salient through task manipulations to properties of social stimuli that are of apparent inherent interest.

This, then, raises the question of what the direction of effects we obtain means in terms of attentional deployment. Larger N100s (Experiment 2) and P200s (Experiments 1 and 2) to Blacks but larger N200s to Whites were obtained both here and in past studies (Ito et al., 2004; Ito \& Urland, 2003). For gender effects, N200s were consistently larger to females, but effects were more variable in the P200. In Experiment 2, gender interacted with race, but in two prior studies, P200s have been larger to males than to females (Ito \& Urland, 2003). Our interpretation of these effects is admittedly preliminary at this point, but extant ERP and social perception research provides a basis for linking earlier effects (N100 and P200) with vigilance and later effects (N200) with known tendencies to direct more attention to racial ingroup members and females.

The association of the N100 and P200 effects with a coarse vigilance effect is based, in part, on the time course of the effects. At initial stages of perception, wariness toward certain classes of stimuli is a reasonable perceptual default. In American culture, stereotypes of Blacks include aspects of aggressiveness and violence, and stereotypes of men include more reference to power and strength than those about women do, suggesting that vigilance mechanisms would preferentially orient to these two types of targets. More generally, none of the participants in these experiments were Black, so attention to Blacks could have been driven solely by their status as outgroup members. This interpretation is also con- sistent with findings of affective modulation of ERP responses as early as $100 \mathrm{msec}$ (Pizzagalli, Regard, \& Lehmann, 1999; Smith, Cacioppo, Larsen, \& Chartrand, 2003), and, in particular, with findings that more negative stimuli attract more attention (Carretié, Martin-Loeches, Hinojosa, \& Mercado, 2001; Carretié, Mercado, Tapia, \& Hinojosa, 2001; Smith et al., 2003). It is also consistent with the greater variability in early attentional effects for gender than for race. Blacks are very consistently associated with concepts directly related to threat (e.g., violence), whereas males are associated with concepts that certainly relate to threat (e.g., strength) but are not themselves directly threatening. Moreover, the participants constantly interact with males (and many were themselves male). Consequently, the tendency to be vigilant when encountering certain racial groups may be stronger and more consistent than the association with males, producing earlier and more consistent race effects.

Although race (and gender) may provide schematic cues relevant to vigilance, the need for continued vigilance in these studies is low. In this context, we believe that initial covert orientation to potentially more threatening racial and gender groups can switch to greater attention to racial ingroup members and females. For race, this is consistent with a large body of behavioral effects suggesting a spontaneously deeper encoding of racial ingroup members, as shown in better memory for racial ingroup members (e.g., Levin, 2000). Perception of racial ingroup members is also associated with greater activation in face-sensitive areas (the fusiform face area), as compared with perception of outgroup members, which predicts better memory for ingroup exemplars (Golby, Gabrieli, Chiao, \& Eberhardt, 2001). Given the time course following initially greater attention to outgroup members, the N200 results may reflect this. We are less certain what the larger N200s to females reflects. Processing biases do sometimes favor female targets (Lewin \& Herlitz, 2002; McKelvie, 1981; McKelvie, Standing, St. Jean, \& Law, 1993), but these effects are more variable than race-processing differences. Future research will therefore be needed to determine the exact psychological meaning of the particular race and gender effects we obtained. It will also be interesting to determine whether the race and gender effects we obtained represent the same psychological mechanisms or different mechanisms that simply manifest with the same time course. Ancillary analyses from Experiment 2 are consistent with the latter possibility. Specifically, correlations were computed to assess the degree to which greater attention to males in the P200 was correlated with greater attention to females in the N200. We performed these correlations with the P200 effects because, although we did not obtain a target gender main effect in this study, the P200 was the point at which target gender first modulated responses and, in prior studies, P200s have been larger to males (Ito \& Urland, 2003). The magnitude of these two target gender main effects was significantly correlated $[r(20)=.46, p<.05]$. Said dif- 
ferently, asymmetric processing in favor of males in the P200 was associated with asymmetric processing of females in the N200. By contrast, these same correlations were not significant along the dimension of race. The degree to which asymmetric processing favored Blacks in the N100 or the P200 was uncorrelated with asymmetric processing favoring Whites in the N200.

\section{Conclusion}

A number of factors, including the tasks used here, can attenuate the influence of stereotypes and prejudice, but the locus of these effects has not been clear. The results of two experiments show that attentional manipulations successful in influencing more downstream aspects of person perception have little effect on early attentional processes. N100 race effects were eliminated in Experiment 1, but visual complexity more so than attentional focus may be responsible. These results therefore suggest that attentional effects on person perception occur after the perceptual encoding of social category information. The results are also relevant to the understanding of basic aspects of face processing. Our demonstration of ERP modulation as a function of social cues before $170 \mathrm{msec}$ - the point previously associated with structural encoding - calls into question the assumption that the structural encoding and the processing of visual semantic cues are independent, sequentially ordered processes (see also Mouchetant-Rostaing \& Giard, 2003; Mouchetant-Rostaing et al., 2000). Moreover, the larger N170s to White faces show that at least under certain conditions, this component can be sensitive to face expertise (i.e., experience) effects. Finally, these results are relevant to studies of nonspatial attention. N100, P200, and N200 effects of race and gender extend this work to show that attentional ERP effects associated with task relevance can also occur to social cues of inherent relevance.

\section{REFERENCES}

Adolphs, R., Tranel, D., \& Damasio, H. (1994). Impaired recognition of emotion in facial expressions following bilateral damage to the human amygdala. Nature, 372, 669-672.

BalConi, M., \& Pozzoli, U. (2003). Face-selective processing and the effect of pleasant and unpleasant emotional expressions on ERP correlates. International Journal of Psychophysiology, 49, 67-74.

Bentin, S., Allison, T., Puce, A., Perez, E., \& McCarthy, G. (1996). Electrophysiological studies of face perception in humans. Journal of Cognitive Neuroscience, 8, 551-565.

BENTIN, S., \& DEOUELL, L. Y. (2000). Structural encoding and identification in face processing: ERP evidence for separate mechanisms. Cognitive Neuropsychology, 17, 35-54.

BREWER, M. B. (1988). A dual process model of impression formation. In T. K. Srull \& R. S. Wyer (Eds.), Advances in social cognition (Vol. 1, pp. 1-36). Mahwah, NJ: Erlbaum.

Bruce, V., \& Young, A. W. (1986). A theoretical perspective for understanding face recognition. British Journal of Psychology, 77, 305-327.

Caharel, S., Poiroux, S., \& Bernard, C. (2002). ERPs associated with familiarity and degree of familiarity during face recognition. International Journal of Neuroscience, 112, 1499-1512.

Caldara, R., Rossion, B., Bovet, P., \& Hauert, C.-A. (2004). Eventrelated potentials and time course of the "other-race" face classification advantage. NeuroReport, 15, 905-910.

Caldara, R., Thut, G., Servoir, P., Michel, C. M., Bovet, P., \& Re-
NAULT, B. (2003). Face versus non-face object perception and the "other-race" effect: A spatio-temporal event-related potential study. Clinical Neurophysiology, 114, 515-528.

Carretié, L., Martín-Loeches, M., Hinojosa, J. A., \& Mercado, F. (2001). Emotion and attention interaction studied through eventrelated potentials. Journal of Cognitive Neuroscience, $\mathbf{1 3}, 1109-$ 1128.

Carretié, L., Mercado, F., Tapia, M., \& Hinojosa, J. A. (2001). Emotion, attention, and the "negativity bias," studied through event-related potentials. International Journal of Psychophysiology, 41, 75-85.

CZIGLER, I., \& GECZY, I. (1996). Event-related potential correlates of color selection and lexical decision: Hierarchical processing or late selection? International Journal of Psychophysiology, 22, 67-84.

Donchin, E. (1981). Surprise! . . Surprise? Psychophysiology, 18, 493-513.

EIMER, M. (1997). An event-related potential (ERP) study of transient and sustained visual attention to color and form. Biological Psychology, 44, 143-160.

EIMER, $\bar{M}$. (2000). Event-related brain potentials distinguish processing stages involved in face perception and recognition. Clinical Neurophysiology, 111, 694-705.

Eimer, M., Holmes, A., \& McGlone, F. (2003). The role of spatial attention in the processing of facial expression: An ERP study of rapid brain responses to six basic emotions. Cognitive, Affective, \& Behavioral Neuroscience, 3, 97-110.

Fiske, S. T., \& NEUBERG, S. L. (1990). A continuum of impression formation, from category-based to individuating processes: Influences of information and motivation on attention and interpretation. $A d-$ vances in experimental social psychology (Vol. 23, pp. 1-74). New York: Academic Press.

Golby, A. J., Gabrieli, J. D. E., Chiao, J. Y., \& Eberhardt, J. L. (2001). Differential responses in the fusiform region to same-race and other-race faces. Nature Neuroscience, 4, 845-850.

Hoffman, E. A., \& HaXBY, J. V. (2000). Distinct representations of eye gaze and identity in the distributed human neural system for face perception. Nature Neuroscience, 3, 80-84.

ITO, T. A., \& CACIOPPO, J. T. (2000). Electrophysiological evidence of implicit and explicit categorization processes. Journal of Experimental Social Psychology, 36, 660-676.

Ito, T. A., ThOMPSON, E., \& CACIOPPO, J. T. (2004). Tracking the timecourse of social perception: The effects of racial cues on eventrelated brain potentials. Personality \& Social Psychology Bulletin, 30, 1267-1280.

ITO, T. A., \& URLAND, G. R. (2003). Race and gender on the brain: Electrocortical measures of attention to race and gender of multiply categorizable individuals. Journal of Personality \& Social Psychology, 85, 616-626.

KANWISHer, N., McDermott, J., \& ChUn., M. M. (1997). The fusiform face area: A module in human extrastriate cortex specialized for face perception. Journal of Neuroscience, 17, 4302-4311.

Kenemans, J. L., KoK, A., \& Smulders, F. T. Y. (1993). Event-related potentials to conjunctions of spatial frequency and orientation as a function of stimulus parameters and response requirements. Electroencephalography \& Clinical Neurophysiology, 88, 51-63.

LEVIN, D. T. (2000). Race as a visual feature: Using visual search and perceptual discrimination tasks to understand face categories and the cross-race recognition deficit. Journal of Experimental Psychology: General, 129, 559-574.

LEWIN, C., \& Herlitz, A. (2002). Sex differences in face recognition: Women's faces make the difference. Brain \& Cognition, 50, 121-128.

LiU, J., Harris, A., \& Kanwisher, N. (2002). Stages of processing in face perception: An MEG study. Nature Neuroscience, 5, 910-916.

Macrae, C. N., \& Bodenhausen, G. V. (2000). Social cognition: Thinking categorically about others. Annual Review of Psychology, 51, 93-120.

Macrae, C. N., Bodenhausen, G. V., Milne, A. B., Thorn, T. M. J., \& CASTElli, L. (1997). On the activation of social stereotypes: The moderating role of processing objectives. Journal of Experimental Social Psychology, 33, 471-489.

McKelvie, S. J. (1981). Sex differences in memory for faces. Journal of Psychology, 107, 109-125. 
McKelvie, S. J., Standing, L., St. Jean, D., \& Law, J. (1993). Gender differences in recognition memory for faces and cars: Evidence for the interest hypothesis. Bulletin of the Psychonomic Society, 31, 447-448.

Morris, J. S., Frith, C. D., \& Perrett, D. I. (1996). A differential neural response in the human amygdala to fearful and happy facial expressions. Nature, 383, 812-815.

Mouchetant-Rostaing, Y., \& Giard, M. H. (2003). Electrophysiological correlates of age and gender perception on human faces. Journal of Cognitive Neuroscience, 15, 900-910.

Mouchetant-Rostaing, Y., Giard, M. H., Bentin, S., Aguera, P. E., \& Pernier, J. (2000). Neurophysiological correlates of face gender processing in humans. European Journal of Neuroscience, 12, 303-310.

NäÄTÄNEN, R., \& GAILlARD, A. W. K. (1983). The orientating reflex and the N2 deflection of the event-related potential (ERP). In A. W. K. Gaillard \& W. Ritter (Eds.), Tutorials in ERP research: Endogenous components (pp. 119-141). New York: North-Holland.

Pizzagalli, D., Regard, M., \& Lehmann, D. (1999). Rapid emotional face processing in the human right and left brain hemispheres: An ERP study. NeuroReport, 10, 2691-2698.

ReEs, G., \& Lavie, N. (2001). What can functional imaging reveal about the role of attention in visual awareness? Neuropsychologia, 39, 1343-1353.

SemLitsch, H. V., Anderer, P., Schuster, P., \& Presslich, O. (1986). A solution for reliable and valid reduction of ocular artifacts, applied to the P300 ERP. Psychophysiology, 23, 695-703.

Smith, N. K., Cacioppo, J. T., Larsen, J. T., \& Chartrand, T. L. (2003). May I have your attention, please: Electrocortical responses to positive and negative stimuli. Neuropsychologia, 41, 171-183.

Stroessner, S. J. (1996). Social categorization by race or sex: Effects of perceived non-normalcy on response times. Social Cognition, $\underline{\mathbf{1 4}}$, 247-276.

TANAKa, J. W., \& Curran, T. (2001). A neural basis for expert object recognition. Psychological Science, 12, 43-47.

WheELER, M. E., \& FISKE, S. T. (2005). Controlling racial prejudice: Social-cognitive goals affect amygdala and stereotype activation. Psychological Science, 16, 56-63.

WiJers, A., Mulder, G., Okita, T., Mulder, L. J. M., \& SchefFERS, M. (1989). Attention to color: An analysis of selection, controlled search, and motor activation, using event-related potentials. Psychophysiology, 26, 89-109.

\section{NOTES}

1. In both experiments, analyses conducted on only the participants reporting their race as White were identical to those in the main text.

2. The mastoid reference was used to allow direct comparison of N100, P200, N200, and P300 results to past social categorization studies (Ito \& Urland, 2003). Although this deviates from the frequently used nose reference in N170 studies and may result in smaller N170 amplitudes, the N170 was visible at temporal sites and was sensitive to experimental manipulations (see the Results section).

3. Although the P 300 had a latency longer than $300 \mathrm{msec}$, we used the P300 name because its scalp distribution and response to psychological processes mirror the classic $\mathrm{P} 300$ component.

4. The N200 also showed evidence of the influence of dotted stimuli, in the form of a significant dot $\times$ phase interaction $[F(1,26)=5.21$, $p<.05]$. N200s were bigger for nondotted stimuli in Phase 1 but were larger for dotted stimuli in Phase 2 (the social categorization task). This interaction was qualified by a significant dot $\times$ phase $\times$ Phase 1 task triple interaction $[F(1,26)=8.22, p<.01]$, indicating that the dot $\times$ phase interaction above held only for those participants assigned to the dot task condition, whereas the participants in the vegetable task condition showed consistently bigger N200s for dotted stimuli across phases. Note that none of these qualified the race effects reported in the text.

5. It is also possible that sensitization played a role in producing the phase effects, since the race categorization task always occurred last. However, if order effects did occur, we might have expected a habituation effect, with smaller effects in the second phase of the experiment.

There were also effects of dot presence, indicating that when stimuli with dots were embedded within contexts that did not have dots, P300s were increased, especially among the participants in the dot categorization condition. These effects replicate past findings showing P300 sensitivity to physical inconsistencies in stimuli (cf. Donchin, 1981). In no case did these interact with target or context race, so the effects will not be discussed further.

6. N100 and P200 analyses both revealed main effects of context race $F(1,21)=18.32$ and 10.17 , respectively; $p$ s $<.005]$. N100s were larger in the White than in the Black context $(M \mathrm{~s}=-7.82$ and $-6.55 \mu \mathrm{V}$, respectively), but P200s were larger in the Black than in the White context $(M \mathrm{~s}=8.39$ and $7.52 \mu \mathrm{V}$, respectively).

(Manuscript received June 9, 2004;

revision accepted for publication November 8,2004 .) 